\title{
Минералогия и металлогенические перспективы Иокирантских полиметаллических проявлений (Карелия, Приладожье)
}

\author{
Иващенко В.И. \\ Институт геологии КарНЦ РАН, Петрозаводск, ivashche@krc.karelia.ru
}

\begin{abstract}
Аннотация. Детально охарактеризована минералогия рудопроявлений. Методами LA-ICP-MS анализа в сфалерите, галените, халькопирите и пирите определены средние содержания элементов-примесей, среди которых наиболее относительно высокие значения характерны для $\mathrm{Au}, \mathrm{Ag}, \mathrm{Bi}, \mathrm{Tl}, \mathrm{Sb}$. Впервые для рудных объектов Карелии установлен Al-F титанит (гротит). Особенности его развития указывают на проявление позднего прогрессивного по температурным условиям процесса, потенциально способного к ремобилизации полиметаллических руд и формированию $\mathrm{Au}-\mathrm{Ag}$-сульфидного оруденения кварцево-жильного типа.

Ключевые слова: Карелия, Приладожье, Иокирантские рудопроявления, Al-F титанит (гротит), сфалерит, галенит, золото, серебро.
\end{abstract}

\section{Mineralogy and metallogenic prospects of the Jokiranta base-metal occurrences, Karelia, Lake Ladoga Region (Priladozhye)}

\section{Ivashchenko V.I.}

Institute of Geology, KarRC, RAS, Petrozavodsk, ivashche@krc.karelia.ru

\begin{abstract}
The mineralogy of the ore occurrences is described in detail. Average impurity element concentrations, in which the highest values are shown by $\mathrm{Au}, \mathrm{Ag}, \mathrm{Bi}, \mathrm{Tl}$ and $\mathrm{Sb}$, were estimated by La-ICP-MS methods for sphalerite, galena, chalcopyrite, and pyrite. Al-F titanite (grothite) was revealed in the Karelia ore occurrences for the first time. Its evolution pattern indicates a late process, which is prograde in terms of its temperature conditions and is capable of remobilizing base-metal ores and forming Au-Ag-sulphide mineralization of quartz veined type.

Keywords: Karelia, Priladozhye, Jokiranta ore occurrences, Al-F titanite (grothite), sphalerite, galena, gold, silver.
\end{abstract}

Иокирантские полиметаллические проявления (Иокиранта, Вайтасаари и др.) приурочены к С3 обрамлению одноименного гнейсогранитного купола (рис. 1). Они представляют собой верхние уровни скарноворудной системы свекофеннских посторогенных ( 1.8 млрд. лет) гранитоидов (Иващенко, 1987). Полиметаллическое оруденение, сопровождающееся флюоритовой, баритовой и шеелитовой минерализацией, сосредоточено в окварцованных эпидотизированных и амфиболизированных пироксеновых скарнах и серпентинизированных кальцифирах, образованных по карбонатным породам сортавальской серии, а также в более низкотемпературных метасоматитах (актинолит, хлорит, пренит, серицит, кварц), развивающихся по ним, и в кварцевых жилах.

Буровыми скважинами (Карельская ГЭ) крутопадающий (40-80 на запад) рудоносный горизонт прослежен по простиранию на 7 км до глубины 150-200 м. Его мощность на севере Иокирантской структуры составляет 60-70 м, на юге - 20-30 м. В пределах этого горизонта установлено 8 линзовидных рудных тел мощностью 5-10 м и протяженностью несколько десятков метров, в составе тел доминирует минеральная ассоциация кислотной стадии (кварц, серицит, карбонат, флюорит, барит, альбит) с реликтами измененных скарновых минералов и полиметаллическим оруденением. Встречаются гнезда (до $1.5 \times 2.0$ м) богатых руд с содержанием свинца и цинка $>10 \%$, вольфрама - до $0.6 \%$, золота - до 0.25 г/т, а также линзовидно-жильные обособления мощностью до 1 м кварц-флюоритового или баритового состава, в которых сульфиды сосредоточены только в зальбандах. В районе плотины на р. Китенъйоки известна субсогласная мономинеральная баритовая жила мощностью 0.5-1 м, приуроченная к контактовой зоне купольных гнейсогранитов и амфиболовых сланцев сортавальской серии. Барит содержит около 2 \% $\mathrm{Sr}$. Амфиболовые сланцы вблизи жилы обильно минерализованы сульфидами, содержат шеелит, а на удалении в 20-30 м рассекаются многочисленными зонами окварцевания, милонитизации и диафтореза. 


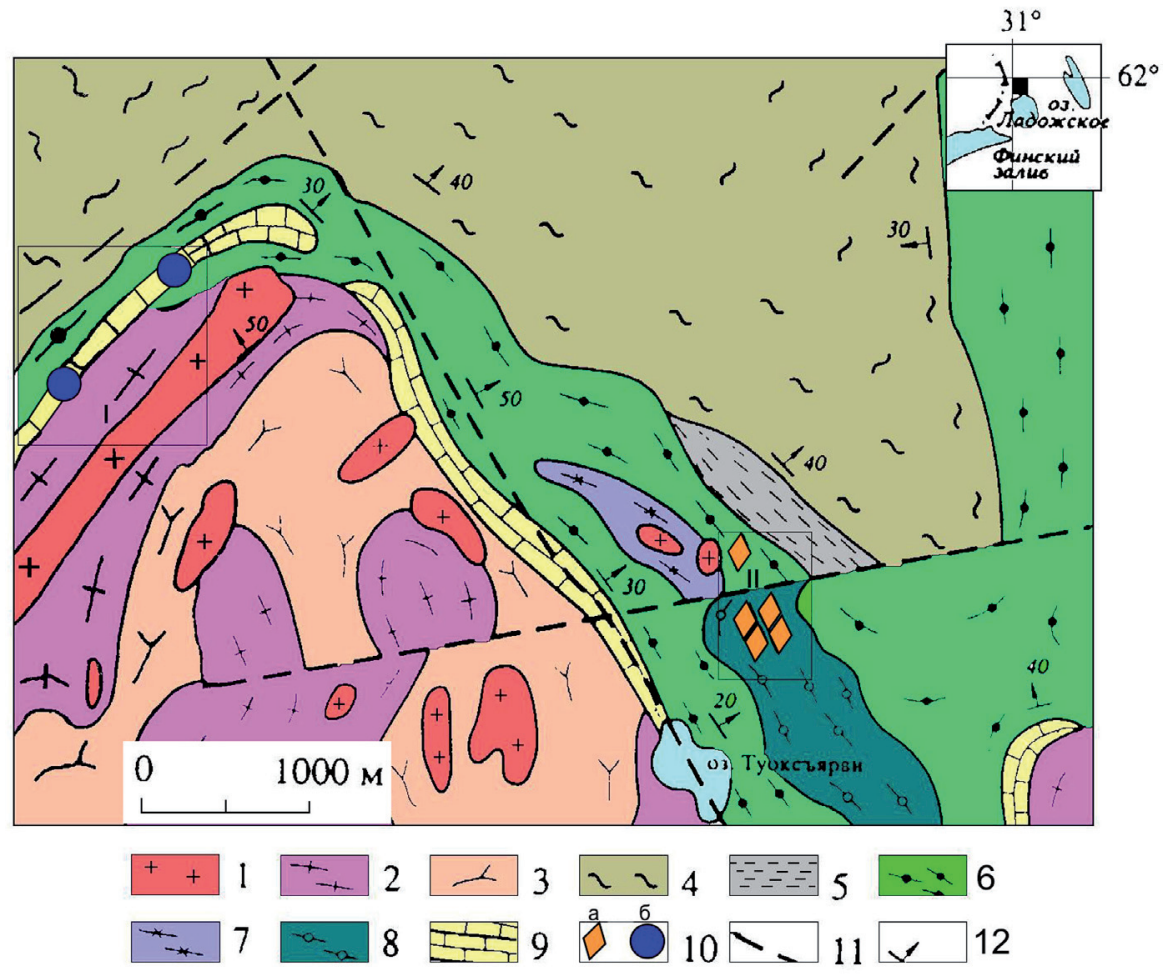

Рис. 1. Схема геологического строения северной части Иокирантского гнейсогранитного купола.

1 - плагиомикроклиновые граниты; 2 - гнейсограниты и мигматиты по вулканогенно-терригенным образованиям сортавальской и ладожской серий; 3 - мигматиты по основным вулканитам сортавальской серии; 4 - гранат- и андалузитсодержащие кварц-биотитовые сланцы с прослоями кварцитопесчаников (ладожская серия); 5-9 - сортавальская серия: 5 - графитсодержащие кварц-слюдистые и амфиболовые сланцы, 6 - амфиболовые сланцы и полевошпатовые амфиболиты с прослоями кварц-слюдистых сланцев, 7 - плагиофировые базальты и амфиболовые сланцы по ним, 8 - шаровые лавы базальтов, 9 - мраморизованные и скарнированные карбонатные породы, скарны с прослоями сланцев; 10 - рудопроявления: а - редкометальные пегматиты Туоксъярви, б - Иокирантские полиметаллические; 11 - тектонические нарушения; 12 - элементы залегания (сланцеватости) пород.

Fig. 1. Scheme showing the geological structure of the northern Jokiranta gneissose-granite dome.

1 - plagiomicrocline granites; 2 - gneissose-granites and migmatites after the Sortavala and Ladoga Series volcanogenic-terrigenous rocks ; 3 - migmatites after mafic volcanics (Sortavala Series); 4 - garnet- and andalusite-bearing quartzbiotite schists with quartzitic-sandstone interbeds (Ladoga Series); 5-9 - Sortavala Series: 5 - graphite-bearing quartzmica and amphibole schists, 6 - amphibole schists and feldspathic amphibolites with quartz-mica schist interbeds, 7 - plagiophyric basalts and amphibole schists after them, 8 - basaltic pillow lava, 9 - marbled and skarned carbonate rocks, skarns with schist intercalations; 10 - ore occurrences: a - Tuoksjärvi rare-metal pegmatites, 6 - Jokiranta base-metal occurrences; 11 - tectonic dislocations; 12 - mode of occurrence of (schistosity) rocks.

По результатам геолого-разведочных работ, выполненных Карельской ГЭ в семидесятые годы прошлого века, прогнозные ресурсы Иокирантских проявлений составили для цинка 64700 т, для свинца 54715 т. Рудопроявления признаны неперспективными.

На современном этапе исследований, проведенных в аналитическом центре ИГ КарНЦ РАН с использованием квадрупольного масс-спектрометра X-SERIES 2 Terhmo Scientific, сканирующего электронного микроскопа VEGA II LSH (Tescan) с энергодисперсионным микроанализатором INCA Energy 350, приставки лазерной абляции UP-266 Macro (New Wave Research) к квадрупольному масспектрометру X-SERIES 2 Terhmo Scientific, получены прецизионные минералого-геохимические данные по рудным метасоматитам Иокирантских проявлений, раскрывающие их новые металлогенические перспективы. 
В минеральном составе рудовмещающих пород Иокирантских проявлений доминируют кварц, кальцит, ферригастингсит, актинолит, хлорит, менее распространены - флюорит, анкерит, цинк-мусковит и др. (табл. 1). Главными рудными минералами являются сфалерит и галенит, второстепенными - халькопирит, пирит, пирротин и др. (табл. 1).

Таблица 1. Видовой минеральный состав Иокирантских полиметаллических проявлений.

Table 1. Mineral composition of the Jokiranta base-metal occurrences.

\begin{tabular}{|c|}
\hline Главные рудные минералы \\
\hline Сфалерит $\left(\mathrm{Zn}_{0.81-0.98} \mathrm{Fe}_{0.02-0.19}\right)$, галенит \\
\hline Второстепенные рудные и акцессорные минералы \\
\hline $\begin{array}{l}\text { Халькопирит, пирит, пирротин, борнит, халькозин, кубанит, магнетит, шеелит, зейрегит, барит } \\
\text { (Sr } 2 \text { \%), молибденит, виллемит, цинкозит, англезит, церуссит, цинкохромит, массикот, гидрогетит, } \\
\text { серебро и висмут самородные, гротит (Al 4-4.6 \%, F 3.1-3.6 \%), апатит (F до 4.6 \%), торит. }\end{array}$ \\
\hline Минералы рудовмещающих пород \\
\hline $\begin{array}{l}\text { Кварц, кальцит, актинолит (mg\# 0.4-0.5), Fe-гастингсит (mg\# 0.2-0.5, Cl 0.67 \%), эпидот (f 0.10-0.15), } \\
\text { диопсид, анкерит, хлорит (mg\# 0.4-0.5), калиевый полевой шпат, флюорит, пренит, серицит, цинк- } \\
\text { мусковит (Zn до } 7 \text { \%) }\end{array}$ \\
\hline
\end{tabular}

Галенит и сфалерит представлены несколькими генерациями. Сфалерит-I (Fe 9 \%) - темнокоричневый до черного встречается в виде кристаллически-зернистых агрегатов с характерной спайностью. Он рассекается прожилками более светло окрашенного (коричневого) сфалерита-ІІ и галенита. Сфалерит-III ( $\mathrm{Fe}<2$ \%) - светло-желтый мелкокристаллический образует рассеянную вкрапленность и микропрожилки. По содержанию элементов-примесей сфалериты разных генераций отличаются несущественно, но наиболее важными в металлогеническом аспекте элементами ( $\mathrm{Au}, \mathrm{Ag}, \mathrm{In})$ обогащен сфалерит-II (табл. 2).

Таблица 2. Средние содержания (г/т) элементов-примесей в главных рудных минералах Иокирантских проявлений (LA-ICP-MS анализ).

Table 2. Average impurity element concentrations $(\mathrm{g} / \mathrm{t})$ in major ore minerals from the Jokiranta occurrences (LA-ICP-MS analysis).

\begin{tabular}{|c|c|c|c|c|}
\hline Элементы & $\begin{array}{c}\text { Сфалерит-2 } \\
16 \text { ан. }\end{array}$ & $\begin{array}{c}\text { Галенит-1 } \\
8 \text { ан. }\end{array}$ & $\begin{array}{c}\text { Халькопирит } \\
9 \text { ан. }\end{array}$ & $\begin{array}{c}\text { Пирит } \\
13 \text { ан. }\end{array}$ \\
\hline $\mathrm{Mn}$ & 335.5 & 194.5 & 72.6 & 80.2 \\
\hline $\mathrm{Co}$ & 1348.9 & 263.5 & 901.1 & 327.9 \\
\hline $\mathrm{Ni}$ & 100.48 & 94.4 & 46.6 & 92.3 \\
\hline $\mathrm{Cu}$ & 25.2 & 77.8 & $>30 \%$ & 71.7 \\
\hline $\mathrm{Zn}$ & $>50 \%$ & 1839.0 & 129.8 & 16.8 \\
\hline $\mathrm{Ga}$ & 15.1 & 13.6 & 15.9 & 19.9 \\
\hline $\mathrm{Ge}$ & 39.5 & 27.7 & 22.8 & 25.1 \\
\hline $\mathrm{As}$ & 63.2 & 84.2 & 255.6 & 205.0 \\
\hline $\mathrm{Ag}$ & 9.2 & 827.4 & 21.6 & 9.8 \\
\hline $\mathrm{Cd}$ & 21197.5 & 210.9 & 31.7 & 18.2 \\
\hline $\mathrm{In}$ & 27.0 & 12.9 & 6.2 & 5.3 \\
\hline $\mathrm{Sn}$ & 7.6 & 11.3 & 49.4 & 47.3 \\
\hline $\mathrm{Sb}$ & 3.8 & 494.0 & 3.2 & 4.0 \\
\hline $\mathrm{Te}$ & 2.9 & 67.4 & 10.8 & 5.6 \\
\hline $\mathrm{Au}$ & 0.4 & 7.4 & 1.1 & 0.6 \\
\hline $\mathrm{Tl}$ & 2.0 & 189.5 & 5.2 & 2.3 \\
\hline $\mathrm{Pb}$ & 11713.2 & $>80 \%$ & 47.7 & 35.9 \\
\hline $\mathrm{Bi}$ & 3.5 & 2374.4 & 0.7 & 0.6 \\
\hline
\end{tabular}


Галенит-1 - крупнокристаллический (до 1 см), образует линзовидно-прожилковидные обособления мощностью 2-8 см, в которых сфалерит практически отсутствует. Галенит-2 слагает тонкие (до 0.1 мм) каймы вокруг зерен сфалерита-1.

По результатам LA-ICP-MS анализа в сфалерите-2, галените-1, халькопирите и пирите установлены повышенные и высокие средние содержания ряда рудных элементов (табл. 2). Наиболее характерными для сфалерита являются Cd (2 \%), In (27 г/т), Co (1349 г/т); для галенита - Ag (827 г/т), $\mathrm{Au}(7.4$ г/T), Bi (2374 г/T), Sb (494 г/т), Tl (190 г/т); для халькопирита и пирита - Au 1.1, 0.6 г/т и Ag 21.6, 9.8 г/т.

Среди второстепенных рудных минералов Иокирантских проявлений наиболее важное генетическое значение имеют серебро и висмут самородные и гротит - титанит с высокими концентрациями $\mathrm{Al}$ и $\mathrm{F}$ (первая находка в рудных объектах Карелии).

Впервые гротит был установлен в высокобарных (до 30 кбар) метаморфических породах (Franz, Spear, 1985) и некоторое время считался минералом-индикатором проявления высоких давлений. Однако впоследствии он был обнаружен в разнообразных по условиям формирования породах, в том числе низкобарных - в гранитах и апоскарновых грейзенах (Enami et al., 1993), в метасоматитах золоторудных месторождений (Вах и др., 2009), а нижний температурный уровень его образования хотя и не определен однозначно, но большинством исследователей (Enami et al., 1993; Вах и др., 2009; Авченко и др., 2012 и др.) оценивается около $400^{\circ}$ С. При этом основным фактором, обусловливающем образование гротита в различных минеральных ассоциациях считается активность фтора минералообразующего флюида (Авченко и др., 2012).

Гротит в рудах Иокирантских проявлений образует отдельные линзовидные зерна размерностью от 20-30 мкм до 1-2 мм. Он не является продуктом замещения титансодержащих минералов, а особенности его выделения отчетливо указывают на его наложенный характер. Гротит образовался после хлорита (рис. 2 А), халькопирита и сфалерита первой и второй генераций (рис. 2 Б). Местами он ассоциирует с калиевым полевым шпатом и $\mathrm{Zn}$-мусковитом (рис. 2 В). Содержания $\mathrm{Al}$ и $\mathrm{F}$ в нем изменяются незначительно (табл. 3).

Согласно хлоритовому (Bourdelle et al., 2013) и $\mathrm{Ga} / \mathrm{Ge}$ сфалеритовому (Moller, 1985) геотермометрам завершающая стадия формирования полиметаллического оруденения на Иокирантских проявлениях происходила при температуре $135-190^{\circ} \mathrm{C}$, то есть значительно ниже температурных условий образования гротита, развивавшегося отчетливо позже хлорита и сфалерита первой и второй ге-
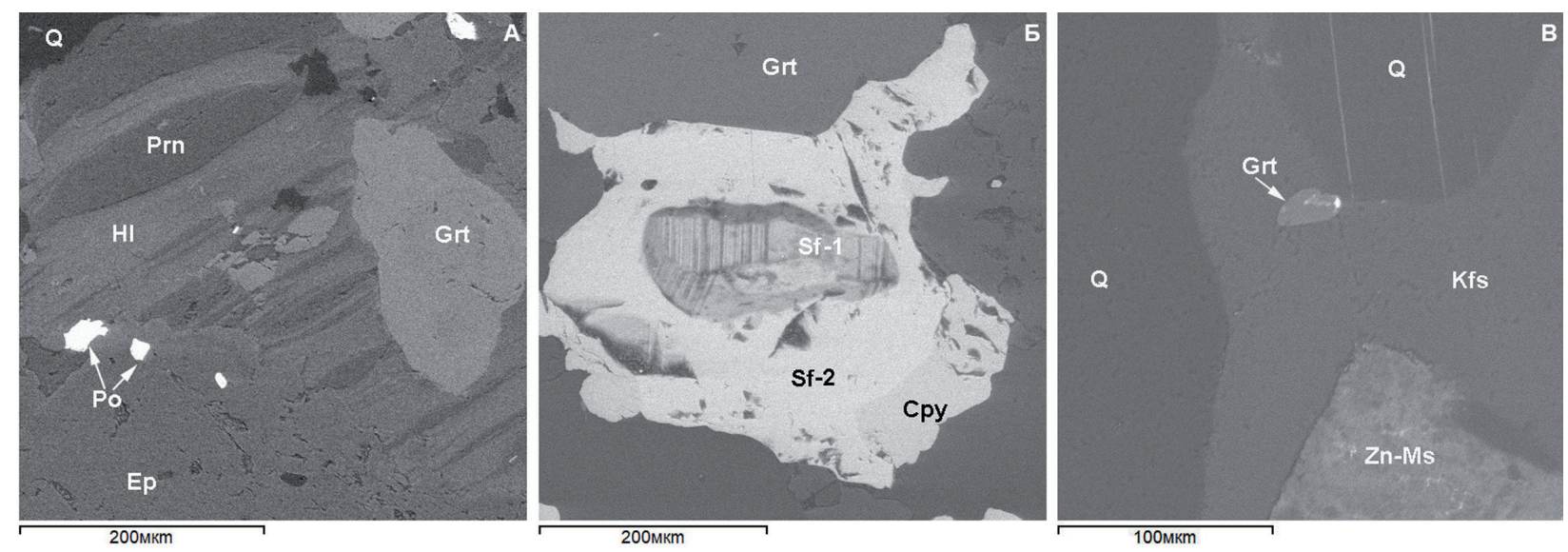

Рис. 2. Формы выделения и минеральные ассоциации гротита в полиметаллических рудах Иокирантских проявлений. BSE-фото. Сру - халькопирит, Еp - эпидот, Grt - гротит, Hl - хлорит, Kfs - калиевый полевой шпат, $\mathrm{Q}$ - кварц, Po - пирротин, Prn - пренит, Sf - сфалерит, Zn-Ms - цинк-мусковит.

Fig. 2. Forms of grothite aggregates and mineral grothite associations in base-metal ores from the Jokiranta occurrences. BSE-photo. Cpy - chalcopyrite, Ep - epidote, Grt - grothite, Hl - chlorite, Kfs - K-potassium feldspar, Q - quartz, Po - pyrrhotite, Prn - prehnite, Sf - sphalerite, Zn-Ms - zinc-muscovite. 
нераций (рис. 2 А, Б). Это, вероятно, свидетельствует о двухэтапном формировании рассматриваемых рудопроявлений, по сути, об их полихронно-полигенном происхождении.

Таблица. 3. Химический состав (масс. \%) гротита из рудных метасоматитов Иокирантских проявлений.

Table 3. Chemical composition (wt. \% ) of grothite from the Jokiranta metasomatic rocks.

\begin{tabular}{|c|c|c|c|c|}
\hline Компоненты & $7390 \mathrm{~b} / 9-1$ & $7390 \mathrm{~b} / 12-5$ & $7397 \mathrm{j} / 5-2$ & $7390 \mathrm{~d} / 4-1$ \\
\hline $\mathrm{CaO}$ & 30.01 & 27.94 & 28.28 & 27.56 \\
\hline $\mathrm{Al}_{2} \mathrm{O}_{3}$ & 8.22 & 7.66 & 8.97 & 8.90 \\
\hline $\mathrm{TiO}_{2}$ & 27.11 & 29.90 & 27.70 & 28.73 \\
\hline $\mathrm{SiO}_{2}$ & 32.85 & 32.48 & 33.02 & 32,41 \\
\hline $\mathrm{F}$ & 3.09 & 3.55 & 3.38 & 3.16 \\
\hline сумма & 101.28 & 101.53 & 101.35 & 100.76 \\
\hline$-\mathrm{O}=\mathrm{F}_{2}$ & 1.30 & 1.49 & 1.42 & 1.33 \\
\hline сумма & 99.98 & 100,04 & 99.93 & 99.43 \\
\hline \multicolumn{5}{|c|}{ Кристаллохимические коэффициенты } \\
\hline $\mathrm{Ca}$ & 1.14 & 1.06 & 1.07 & 1.05 \\
\hline $\mathrm{Al}$ & 0.31 & 0.29 & 0.34 & 0.33 \\
\hline $\mathrm{Ti}$ & 0.65 & 0.72 & 0.66 & 0.68 \\
\hline $\mathrm{Si}$ & 1.04 & 1.03 & 1.04 & 1.03 \\
\hline $\mathrm{F}$ & 0.31 & 0.36 & 0.34 & 0.32 \\
\hline $\mathrm{OH}$ & 0.69 & 0.64 & 0.66 & 0.68 \\
\hline $\mathrm{O}$ & 4.16 & 4.12 & 4.16 & 4.12 \\
\hline
\end{tabular}

Следовательно, после образования полиметаллического оруденения в обрамлении Иокирантского гнейсогранитного купола был проявлен прогрессивный по температурным условиям процесс, потенциально способный к ремобилизации руд и формированию Au-Ag-сульфидной минерализации кварцево-жильного типа, как в пределах разведывавшегося ранее рудного горизонта, так и во вмещающих его карбонатных породах и амфиболовых и графитсодержащих сланцах. Сходная позиция золотого оруденения с участием гротита установлена на Березитовом месторождении на Дальнем Востоке (Вах и др., 2009; Авченко и др., 2012).

Работа выполнена в рамках темы НИР № АААА-А18-118020290175-2.

\section{Литература}

1. Авченко О.В., Вax А.С., Чудненко К.В., Шарова О.И. Физико-химические условия образования Al-F сфена в рудно-метасоматических породах Березитового месторождения // Геохимия. 2012. № 5. C. $453-469$.

2. Вах А.С., Авченко О.В., Карабцов А.А., Степанов В.А. Первая находка гротита в золоторудных месторождениях // Докл. РАН. 2009. Т. 428. № 3. С. 353-357.

3. Иващенко В.И. Скарновое оруденение олова и вольфрама южной части Балтийского щита (минералогия, петрография, генезис). Л. Изд-во: Наука. 1987. 240 С.

4. Bourdelle F., Parra T., Chopin C., Beyssac O. A new chlorite geothermometer for diagenetic to low-grade metamorphic conditions // Contrib. Mineral. Petrol. 2013. V. 165. P. 723-735.

5. Enami M., Susuki K., Liou J.G., Bird D.K. Al-Fe ${ }^{3+}$ and F-OH substitutions in titanite and constrains on their P-T dependence // Eur. J. Mineral. 1993. V. 5. P. 219-231.

6. Franz G., Spear F. Aluminous titanite (sphene) from the eclogite zome South-Central Tauern Window Austria // Chem. Geol. 1985. V. 50. № 1/3. P. 33-46.

7. Moller P. Development and Application of the $\mathrm{Ga} / \mathrm{Ge}-\mathrm{Geothermometer} \mathrm{for} \mathrm{sphalerite} \mathrm{from} \mathrm{sediment-hosted}$ deposits // Monograph Series on Mineral Deposits 25. Gebruder Borntraeger, Berlin-Stuttgart: 1985. P. 15-30. 